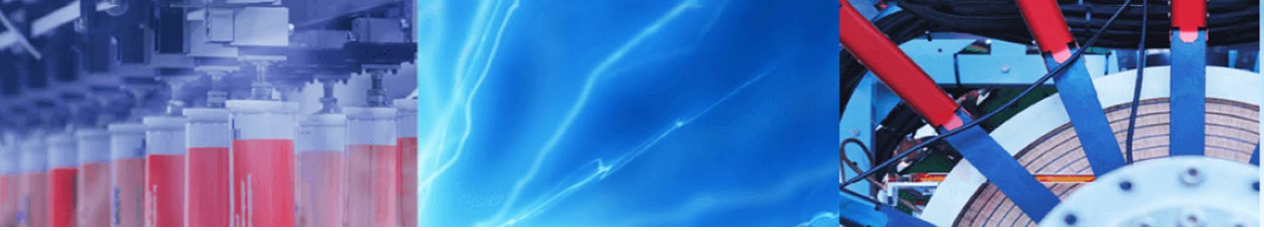

Research Article

\title{
Study on effect of process parameters on tensile properties of compression molded natural fiber reinforced polymer composites
}

\author{
Temesgen Berhanu Yallew ${ }^{1} \cdot$ Eshetie Kassegn $^{1} \cdot$ Sirak Aregawi $^{1} \cdot$ Alula Gebresias $^{1}$
}

Received: 26 August 2019 / Accepted: 22 January 2020 / Published online: 4 February 2020

(c) Springer Nature Switzerland AG 2020

\begin{abstract}
Recently natural fiber reinforced polymer composites are highly employed in the automotive, construction and packaging industrial sectors. Hence, there is huge demand for mechanical property improvement of these natural fiber reinforced polymer composite materials. Desired improvements in mechanical properties can be achieved by optimizing the process parameters while fabricating the composites. In the present experimental endeavor an attempt has been made to fabricate natural fibre reinforced Polymer Matrix Composites (PMCs) with the objective of developing the PMCs with improved tensile property using the compression moulding process. The knowledge of process parameters such as heating temperature $(T)$, compressive pressure $(\mathrm{P})$ and molding time $(\mathrm{t})$ of the polymer sheets and the developed composites are necessary to make a part of improved mechanical properties. The processing parametric conditions and techniques for the fabrication of the composite have been identified by measurements of tensile properties and micrograph image observation.
\end{abstract}

Keywords Molding parameters · Morphology $\cdot$ Natural fibers $\cdot$ Polypropylene $\cdot$ Tensile behavior $\cdot$ SEM

\section{Introduction}

In response to the growing interest in demand for natural fiber reinforced composite materials, researchers have been doing researches aimed at supplying ever-improved application for the automotive, construction and packaging industries. A major challenge in the fabrication of composites has been how to achieve a homogeneous distribution of matrix in the reinforcement material. Generally, the main function of fibers is enhancing the strength and stiffness of composites, while that of polymer matrix include binding fibers together to protect them from damage, and boosting their toughness and their resistance to corrosion and heat. Fiber reinforced composites can be either thermoset or thermoplastic depending on the polymer matrix [1].
To date, thermosetting matrices have been used to fabricate most of the Polymer Matrix Composites (PMCs) materials used in various applications. But thermosets are known to have inherent drawbacks including brittleness, long cure cycles, and difficulty to repair and recycle damaged parts. The thermoplastic matrix composite system is a result of these limitations. Typically, composites fabricated from thermoplastic materials have longer shelf life, greater strain to failure, faster consolidation, superior chemical resistance, better damping characteristics, low noise emission, and better repairability than their thermoset counterparts. Polypropylene (PP) stands out as the most widely used thermoplastic in the industrial sector for its superior wear resistance, lower cost, ease of processability and excellent mechanical properties, among others $[2,3]$.

$\triangle$ Temesgen Berhanu Yallew, temesgenu11@gmail.com; Eshetie Kassegn, keshetie61@yahoo.com; Sirak Aregawi, sir86741@gmail.com; Alula Gebresias, gebresas@gmail.com | ${ }^{1}$ School of Mechanical and Industrial Engineering, Ethiopian Institute of Technology- Mekelle (EiT-M), Mekelle University, Tigray, Ethiopia. 
Higher flexural modulus and impact strengths have made natural fibres superior alternatives to synthetic fibres as reinforcements for polymeric composites. Furthermore, they are eco-friendly, available in abundance, renewable, of lower density, and biodegradable. As biodegradable materials natural fibres contribute to healthy ecosystem while their availability at a lower cost coupled with their excellent performance allows industries garner higher profits. Applications of natural fiber based polymeric composites are found in such products as housing construction materials, furniture, and automotive parts [4-7].

The natural fibres most commonly used to reinforce polymer composites include pineapple leaf, oil palm, hemp, sisal, jute, kapok, rice husk, bamboo, and wood [8]. Natural fibre has shortfalls that may pale their advantages as low thermal resistance, inherent polarity, less dimensional stability, and anisotropic fibre properties. These down sides result in weaker fibre-resin interaction [9].

Usually, it is the efficiency of bonding at the fibre-matrix interfacial boundary that determines the mechanical properties of a natural fibre-polymer matrix composite. The principal function of the interface mainly facilitates the transfer of stress between the fibres across the matrix [10]. Numerous research studies conducted over the past decade have reported successful use of natural fibres as reinforcements to enhance the mechanical properties of the polymer matrix composites [3-7, 10-12].

The demand for bio-based composite materials has been on the rise lately propelled by the urge by many nations to extricate themselves of excessive craving for petroleum and build eco-friendly economies. The world has now found in bio-based composites a potent substitute for glass fiber reinforced composites especially for the demands of the automotive industry. Of course, the exploitation of natural fiber-based materials is by no means a novel venture even in the automotive sector. As early as the $1940 \mathrm{~s}$, natural fibers such as hemp had a powerful advocate in Henry Ford himself. Natural fibers stand in relative superiority to man-made glass fiber on account of their lower cost and density, good specific mechanical properties, lessor energy consumption, carbon sequestration, and biodegradability [13].

European automotive industries have over the last 10 years opted for natural-fiber composites with thermoplastic and thermoset matrices for the manufacture of seat backs, package trays, door panels headliners, dashboards, and interior parts. The process was accelerated by the taking effect of European Union legislation in 2006. According to the legislation, about $80 \%$ of a vehicle should be recyclable by 2006 and $85 \%$ by 2015 , while Japan's had plans to recycle $88 \%$ of a vehicle by 2005 and up to $95 \%$ by 2015 [14].
Manufacturers frustrated by the process inconsistencies inherent in hand-layup, autoclave-based molding processes are strongly attracted by compression moulding process, which in turn has difficulty of controlling flash. Hence, not all of products are suitable for compression molding. In addition to quality specification, process conditions require paying attention to a number of considerations [1]. Researchers have been reporting findings of their experiments on a variety of factors that influence the mechanical properties of natural fibre composites.

Srinivasa et al. [15] studied a compression molding technique with varying process parameters, such as fiber condition (untreated and alkali treated), and fiber loading percentages ( $50 \%$ and $60 \%$ by weight). The developed areca fiber-reinforced composites were then characterized by physical, bending and impact test. The results show that flexural and impact strength increases with increase in the fiber loading percentage. Compared to untreated fiber, significant change in flexural and impact strength has been observed for treated areca fiber reinforcement. The results presented in this work indicate that it is possible to enhance the properties of fiber-reinforced composites through fiber surface modification. The composite can certainly be considered as a very promising material to fabrication of lightweight materials used in automobile body building, office furniture packaging industry, partition panels, etc.

Saravanan and Dhurai [16] examined the effect of temperature, pressure, and fiber treatment time on impact strength of jute fiber reinforced polypropylene composite. Composite specimens were prepared by using compression moulding process. Composites fabricated at the temperature of $\left(165^{\circ} \mathrm{C}\right)$, pressure $(8.13 \mathrm{bar})$ and fiber treatment time ( $3 \mathrm{~min}$ ) exhibited the best impact strength properties.

Zampaloni et al. [14] studied manufacturing problems and solutions discussing a study in which they successfully produced kenaf-polypropylene natural fiber composites. The composite fabricated by compression molding using both $30 \%$ and $40 \%$ fiber content by weight was found to provide adequate reinforcement boosting the strength of the polypropylene powder. Both tensile and flexural strengths of the kenaf-polypropylene composites compression-molded in the study were found to be very similar to those produced form $40 \%$ of flax and hemp polypropylene. By contrast, the tensile strength of the kenaf-polypropylene was higher and its flexural strength almost doubles those of coir and sisal reinforced composites. The study further showed that kenaf-Polypropylene's modulus/cost and specific modulus were superior to that of sisal, coir, hemp, flax, and E-glass. Put otherwise, the $30 \%$ by weight kenaf polypropylene composite compared 
favourably with the more common $40 \%$ fiber by weight hemp and flax fiber polypropylene composites.

Dweib et al. [17] made an effort to develop bio-fiber composite roofing, structural panels and unit beams were manufactured out of soybean oil based resin and natural fibers (flax, cellulose, pulp, recycled paper, chicken feathers) using vacuum assisted resin transfer molding (VARTM) technology. Physical and chemical investigations and mechanical testing of the beams yielded results well in line with desired structural performance. Natural fiber reinforcement of 20-55 wt\% fiber increased the flexural modulus to 2-6 GPa. The same resin reinforced with woven E-glass gave a flexural modulus of $17 \mathrm{GPa}$. Using the composite material for building introduced advantages including better strength and stiffness, better endurance in the face of severe weather conditions, and design flexibility.

Torres et al. [18] investigated plant fibers reinforced starch polymers processed by compression molding, using sweet potato, and cornstarch as matrices. Three types of plant fibers were namely sisal, jute, and cabuya, used in the fabrication of composites at fiber volumes ranging from 2.5 to $12.5 \% \mathrm{w} / \mathrm{w}$. Plasticizers like water and glycerol were used for the polymers. Mechanical properties were assessed by tensile and impact tests. In both cases, improved mechanical properties were found at increasing fiber volumes. Tensile strength appeared to be markedly improved with the addition of $10 \%$ by weight of sisal fibers, while the best results for impact strength were obtained for cabuya fibers. The processing parameters were determined experimentally considering the gelatinization temperature and thermal degradation of the fibers. Whereas, almost $100 \%$ improvement in tensile strength of potato starch could be achieved with a $10 \% \mathrm{w} / \mathrm{w}$ of sisal fibers, while for jute and cabuya fibers at $12.5 \% \mathrm{w} / \mathrm{w}$, improvements in tensile strength of 54 and $15 \%$, respectively were reported. Composites specimen based on jute and cabuya fibers with potato starch displayed improvements in impact strength of almost 100 and $200 \%$, respectively, with the unreinforced matrix.

Takemura and Minekage [19] investigated the effect of compression process parameters on the tensile properties of hemp fiber reinforced composites. Compression molding was used to process the composites where the molding temperature and its heating time were changed from 160 to $190^{\circ} \mathrm{C}$ and from 15 to $25 \mathrm{~min}$, respectively. In their findings the tensile property of hemp fiber reinforced polypropylene was found to have improved compared with polypropylene bulk. The composite was 2.6 times stronger than the resin bulk specimen. The optimal molding temperature and duration were found to be under $180^{\circ} \mathrm{C}$ and $20 \mathrm{~min}$ for hemp fiber reinforced green composite.

Khondker et al. [20] studied composite specimen fabricated at different processing conditions. Jute/PP composite specimens revealed better mechanical properties under the optimal processing conditions identified. The static mechanical properties of unidirectional jute/PP composites improved considerably compared to those of the virgin PP materials.

Though researchers have been reporting findings of their experiments; no study has been done to date on the study of process parameters aimed at improving the mechanical properties.

In this study, a woven natural fiber (hemp, jute and sisal) reinforced polymer composites under controlled process have been manufactured. Mechanical properties of the developed composites have been evaluated. The optimal process parameters applied in order to improve the mechanical properties without damaging the natural fibre reinforcement has been addressed to investigate an efficient employment of the fabricated composite and assess the possibility of using these materials in a number of applications. SEM images have been studied to fully understand the mechanical behaviour of developed composites under the various molding conditions.

\section{Experimental details}

\subsection{Materials}

The raw materials used to develop the experimental specimen composites are depicted in Table 1.

Table 1 Materials used

\begin{tabular}{|c|c|c|c|}
\hline Material & Type & Property & Supplied by \\
\hline Matrix & $\begin{array}{l}\text { Polypro- } \\
\text { pylene } \\
\text { (PP) }\end{array}$ & $\begin{array}{l}\text {-Homo polymer pellets } \\
\text {-Density } 0.905 \mathrm{~g} / \mathrm{cm}^{3} \text {. } \\
\text {-Melting temperature } \\
\left(\mathrm{T}_{\mathrm{m}}\right) 165^{\circ} \mathrm{C} \\
\text {-Melt Flow Index (MFI) } \\
10.5 \mathrm{~g} / 10 \mathrm{~min}\end{array}$ & $\begin{array}{l}\text { Bruh Tesfa Irrigation and Water Technology. In the } \\
\text { form of pellets. Mekelle, Tigray, Ethiopia }\end{array}$ \\
\hline \multirow[t]{3}{*}{ Reinforcement } & Hemp & Woven fabric mat form & Extracted fiber suppliers Mekelle, Tigray, Ethiopia \\
\hline & Jute & Woven fabric mat form & \\
\hline & Sisal & Woven fabric mat form & \\
\hline
\end{tabular}




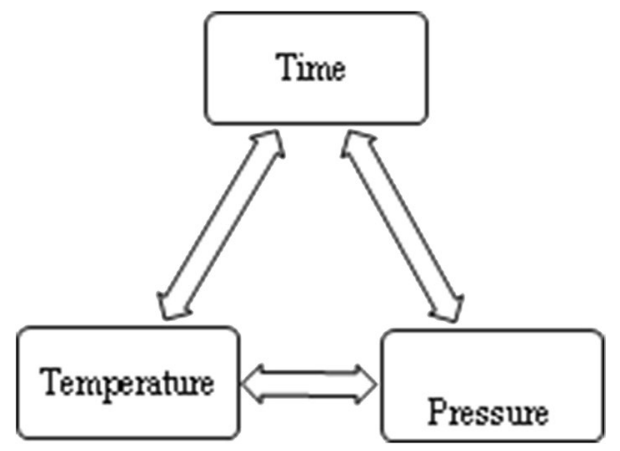

Fig. 1 Basic compression molding process parameters

\subsection{Identifying the process parameters}

Knowing the operating parameters is key in the fabrication of natural fiber reinforced polymer composites using the compression molding process. Properly handled, the various process parameters can result in enhanced composite material characteristics. Indeed, whether the tests conducted on the same material could be reproduced depends up on the homogeneity of materials and their interaction as well as observance of experimental conditions. Figure 1 shows the main process parameters of the compression molding technique.

\subsubsection{Heating temperature}

An important process parameter, it is linked to the amount of heat at which the matrices (polymers) are likely to melt. The processing temperature is mainly influenced by the viscosity of matrix. Change in viscosity affects the distribution of the particle in the matrix. The viscosity of liquid fell with increased processing temperature with more holding time. It is important to keep the amount of polymer pellets uniform in order to get good quality polymer sheets. Failure to keep uniformity results in the clustering of particles here, and there intensifying defects of porosity and inclusion.

\subsubsection{Compressive pressure}

Porosity was the prime defect during the fabrication polymer sheets and composite laminate. Preheating the permanent mold, which would help remove the entrapped gases from the slurry in mold, can prevent this. It also would boost the mechanical properties of the fabricated Polymer sheet as well as composite laminate, while compressing the molten polymer keeps the compressing rate constant, preventing bubbling.

\subsubsection{Curing time}

Curing time refers to the moment of cessation of relative movement between the moving parts of a mold and the instant that pressure is released to cure the resin. Promotes uniform distribution molten polymer into the woven fabric mat reinforcement to create perfect interface bond between reinforcement and matrix. Table 2 indicates selected process parameters.

\subsection{Fabrication procedure}

The following procedure was used in the preparation of the polymer matrix (PP) sheets and the composite laminates.

(a) Fabrication of thermoplastic polymer sheets Indeed, such polymer properties as surface wettability, friction, and adhesion are largely affected by the structures of the polymer surfaces and strong influence in its applications. First, a $1 \mathrm{~mm}$ thick thermoplastic polymer sheets (PP) was made with the help of a compression moulding machine by melting and compressing pre-weighed PP pellets. A new mould was developed to fabricate thermoplastic polymer (PP) of the size $350 \mathrm{~mm} \times 350 \mathrm{~mm} \times 1 \mathrm{~mm}$. Figures $2 \mathrm{a}, \mathrm{b}$ and 3 show the PP pellets and the fabricated thermoplastic sheet respectively; whereas (c) and (d) show the lower and upper fabricated aluminum mould. High attention and care was exercised to obtain micro porous free Polypropylene (PP) sheets. Silicone release agents were also used to maximize process efficiency, minimize scrap and give the specimen a final part surface finish that meets end product requirements.

(b) Preparation of natural fibre reinforced composites The 30\% fiber loading (wt\%) woven fabric mat and the PP sheets were stacked in the mould, while the woven fabric mat was kept between the two PP sheets. The entire assembly was hot pressed with the desired heating temperature, compressive pressure and curing time as shown in Table 2. PP sheets melts and impregnates woven fabric mat resulting in a compaction. The plates were then put under the

Table 2 Compression process parameters

\begin{tabular}{llll}
\hline S. no & $\begin{array}{l}\text { Heating tempera- } \\
\text { ture }\left({ }^{\circ} \mathrm{C}\right)\end{array}$ & $\begin{array}{l}\text { Compressive pres- } \\
\text { sure }(\mathrm{MPa})\end{array}$ & $\begin{array}{l}\text { Curing } \\
\text { time }(\min )\end{array}$ \\
\hline 1 & 165 & 0.5 & 4 \\
2 & 175 & 1.0 & 4 \\
3 & 185 & 1.5 & 4 \\
\hline
\end{tabular}


Fig. 2 Preparation of polymer films a PP pellets. b Fabricated $1 \mathrm{~mm}$ thick polymer film. c Lower mould plate and $\mathbf{d}$ Upper mould plate
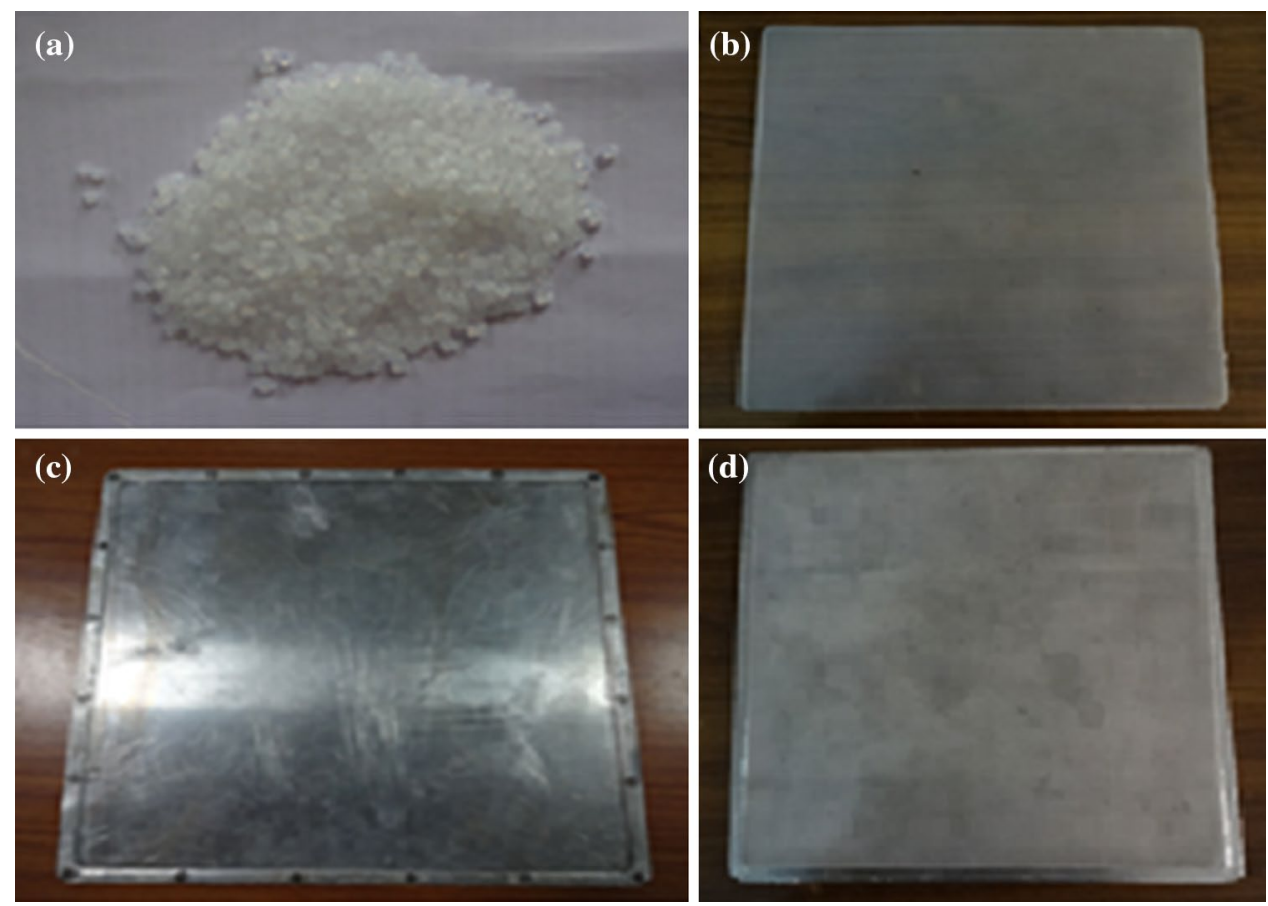

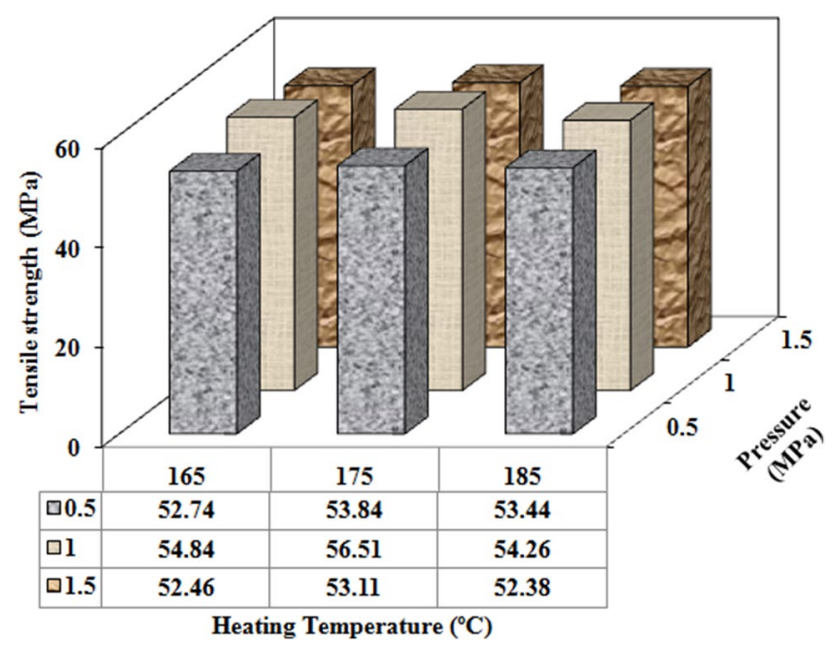

Fig. 3 Variation of tensile strength with heating temperature and pressure for hemp/PP composites

desired specific pressure for a pre-defined time to obtain the moulded product. Finally, the composite laminates were removed after the plates cooled down to optimum temperature and then the pressure was released. Several of such experimental composites were prepared by varying the process parameters temperature, pressure and curing time as shown in Table 2.

\subsection{Tensile behaviour of the fabricated composite laminates}

The mechanical characterizations of the developed composites have been conducted as per ASTM standard and procedures. Representative specimens from various sections of the fabricated composite laminate were cut using circular band saw and tensile specimens were prepared according to ASTM D30396 standard. The size of the samples used for tensile strength test were $250 \mathrm{~mm} \times 24 \mathrm{~mm} \times 4 \mathrm{~mm}$. The tests were done using a Kalpak Computerized Universal testing machines model KIC-2-XXX-C with Series IX software (Canton, MA), which has a maximum capacity of $30 \mathrm{KN}$. All tests were performed with a crosshead speed of $1 \mathrm{~mm} / \mathrm{min}$ at room temperature $\left(25^{\circ} \mathrm{C}\right)$ and at a relative humidity of 50 . Five specimens were tested for each sample and the mean values were reported.

\subsection{Micrograph image observation}

Morphological observation of specimens was carried out at room temperature using model XL 30, Philips Scanning Electron Microscope (SEM). The specimen was coated with a very thin film of gold using Sputter Coater to enhance conductivity before micrographs were taken. 


\section{Results and discussion}

\subsection{Tensile properties}

Tensile strength is materials ability to with stand (resist) failure under pulling (breaking) due to tensile stress. It is an important materials measured property in the construction and other structural applications. In the present study, an investigation of molding conditions on tensile behaviour of fabricated natural fiber reinforced polymer composites has been assessed.

The tensile properties of the developed composites have been compared with each other. The composites laminates were processed with heating temperature range of 165 to $185^{\circ} \mathrm{C}$ and compressive pressure range 0.5-1.5 MPa. The following results were obtained from the current extensive experiments. The fiber (hemp, jute and sisal) composites have shown better tensile strength at $175^{\circ} \mathrm{C}$ of heating temperature and $1 \mathrm{MPa}$ compressive pressure. Tensile strength shows a tendency to decrease its value when the heating temperature and compressive pressure were less than or greater than $175^{\circ} \mathrm{C}$ and $1 \mathrm{MPa}$ respectively. Figures 3,4 and 5 depicts the tensile properties for hemp, jute and sisal fiber reinforced polypropylene matrix fabricated composites respectively. The figures indicates the values of tensile strength with the variations of heating temperature and compressive pressure. The tensile strength data achieved confirm that the sisal fiber obtained more effective as reinforcement in Polypropylene matrix composites fabricated with the current technique.

Figure 3 shows hemp fiber reinforced polypropylene composites. It has been obtained highest tensile strength $(56.51 \mathrm{MPa})$ at $175{ }^{\circ} \mathrm{C}$ heating temperature and $1 \mathrm{MPa}$ compressive pressure molding conditions.

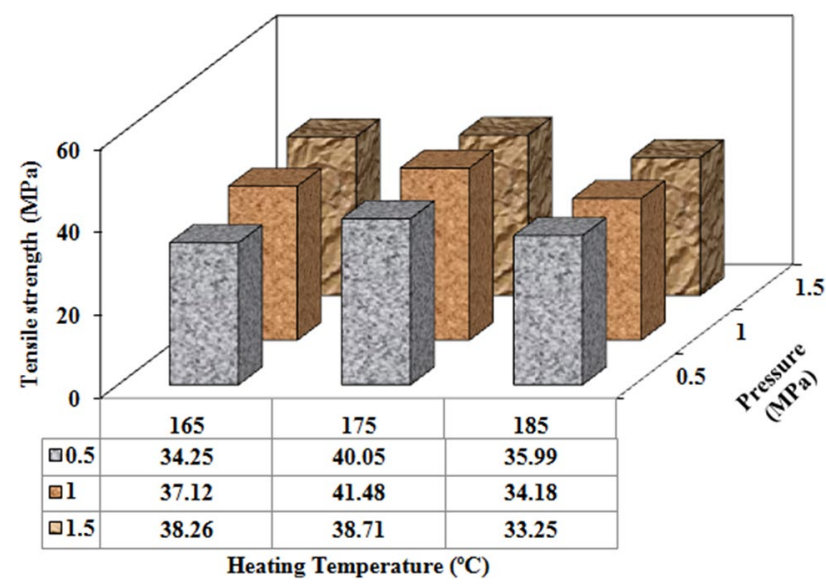

Fig. 4 Variation of tensile strength with heating temperature and pressure for jute/PP composites

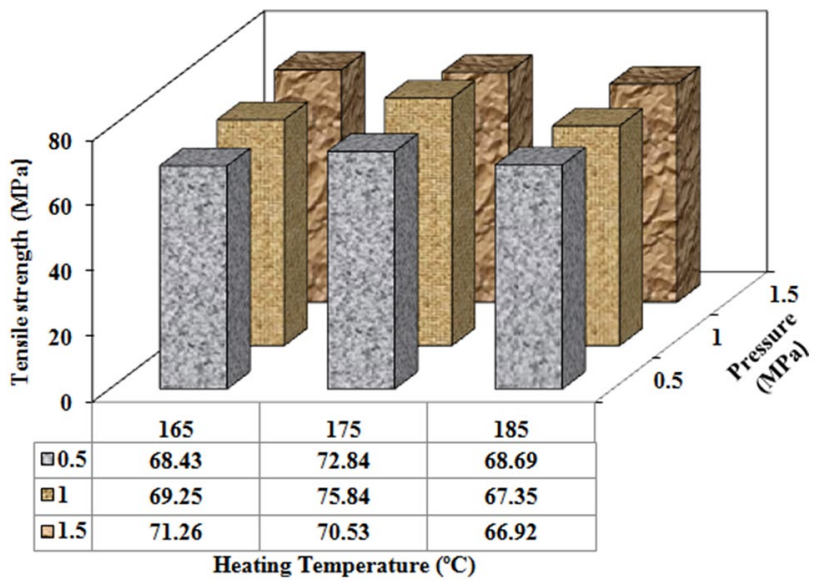

Fig. 5 Variation of tensile strength with heating temperature and pressure for sisal/PP composites

The lowest tensile strength $(52.38 \mathrm{MPa})$ was obtained at heating temperature of $185^{\circ} \mathrm{C}$ and pressure of $1.5 \mathrm{MPa}$ molding conditions. Similarly Figs. 4 and 5 depicts the tensile behaviour variation with molding condition for jute and sisal fiber reinforced polypropylene composites respectively. The highest tensile strengths of $41.48 \mathrm{MPa}$ for jute fiber reinforced composites and $75.84 \mathrm{MPa}$ for sisal fiber reinforced composites were recorded from specimens fabricated at $175^{\circ} \mathrm{C}$ heating temperature and $1 \mathrm{MPa}$ compressive pressure molding conditions. The lowest tensile strength was also obtained at $185^{\circ} \mathrm{C}$ heating temperature and $1.5 \mathrm{MPa}$ pressure for both the jute (33.25 MPa) and sisal (66.92 $\mathrm{MPa}$ ) fiber reinforced composites.

With the set curing (molding) time the heating temperature $165^{\circ} \mathrm{C}$ was not enough for moulding of the composites. As the temperature increases to $175^{\circ} \mathrm{C}$ the heat transferring rate may increase as the result of this tensile strength increases. The experimental results also showed that tensile strength decreases with the higher heating temperature $\left(185^{\circ} \mathrm{C}\right)$. Especially, the decreasing rate of tensile strength was more significant when the fiber was exposed with high compressive pressure (1.5 MPa). This reductions in tensile strength may be due to the thermal degradation of the natural fibers (hemp, jute and sisal) at elevated thermal conditions. In addition at lowest compressive pressure the matrix-fiber interface strength may not be strong as a result lowest strengths obtained. An optimal pressure with improved strength was obtained at a $1 \mathrm{MPa}$ which may be considered as the maximum pressure which can be applied for improving the mechanical properties before damaging the structure of the fibres, so that meaning full reinforcement takes place. Sisal fiber is more effective than the hemp and jute fibers as reinforcement of bio-composites in regard to strengths view point. 


\subsection{Morphological observations}

The Scanning Electron Microscopy (SEM) images of the tensile fractured surface morphologies of the fabricated composites are shown in Fig. 6 . The morphology of the tensile fracture surface shows the phase information reflecting the reasons behind the variation in the mechanical properties of the composites fabricated under different conditions. Significant fiber damage in the composites observed with composites fabricated at the highest temperature and pressure and the effect is clearly depicted in Fig. 6c. More fiber pull out are shown with the lowest process parameters (lowest temperature and pressure); which indicates the weakest fiber interfacial interaction which shows poor mechanical properties as revealed by Fig. 6a micrograph image. Figure $6 \mathrm{~b}$ elaborates the micrograph image for tensile fractured specimen fabricated with optimum values of the process parameters. The fiber bundles are clearly indicated with adequate wetting by the matrix and free from imperfections. This accounts for better interfacial interaction between fiber and PP matrix which leads to better stress transfer and as a result highest tensile strength behaviour.

\section{Conclusions}

In the current experimental study; natural fiber reinforced composites has been fabricated with different molding conditions. The effect of the molding parameters on tensile strength of the fabricated specimens has been investigated. SEM study has been conducted to substantiate the outcomes. From this extensive experimental investigation the following conclusions can be drown.

1. The highest tensile strength has been recorded at $175^{\circ} \mathrm{C}$ heating temperature and $1 \mathrm{MPa}$ compressive pressure molding conditions.

2. The lowest tensile strength has also been obtained at $185^{\circ} \mathrm{C}$ heating temperature and $1.5 \mathrm{MPa}$ pressure molding conditions.

3. Sisal fiber is more effective than the hemp and jute fibers as reinforcement of bio-composites in regard to strengths view point.
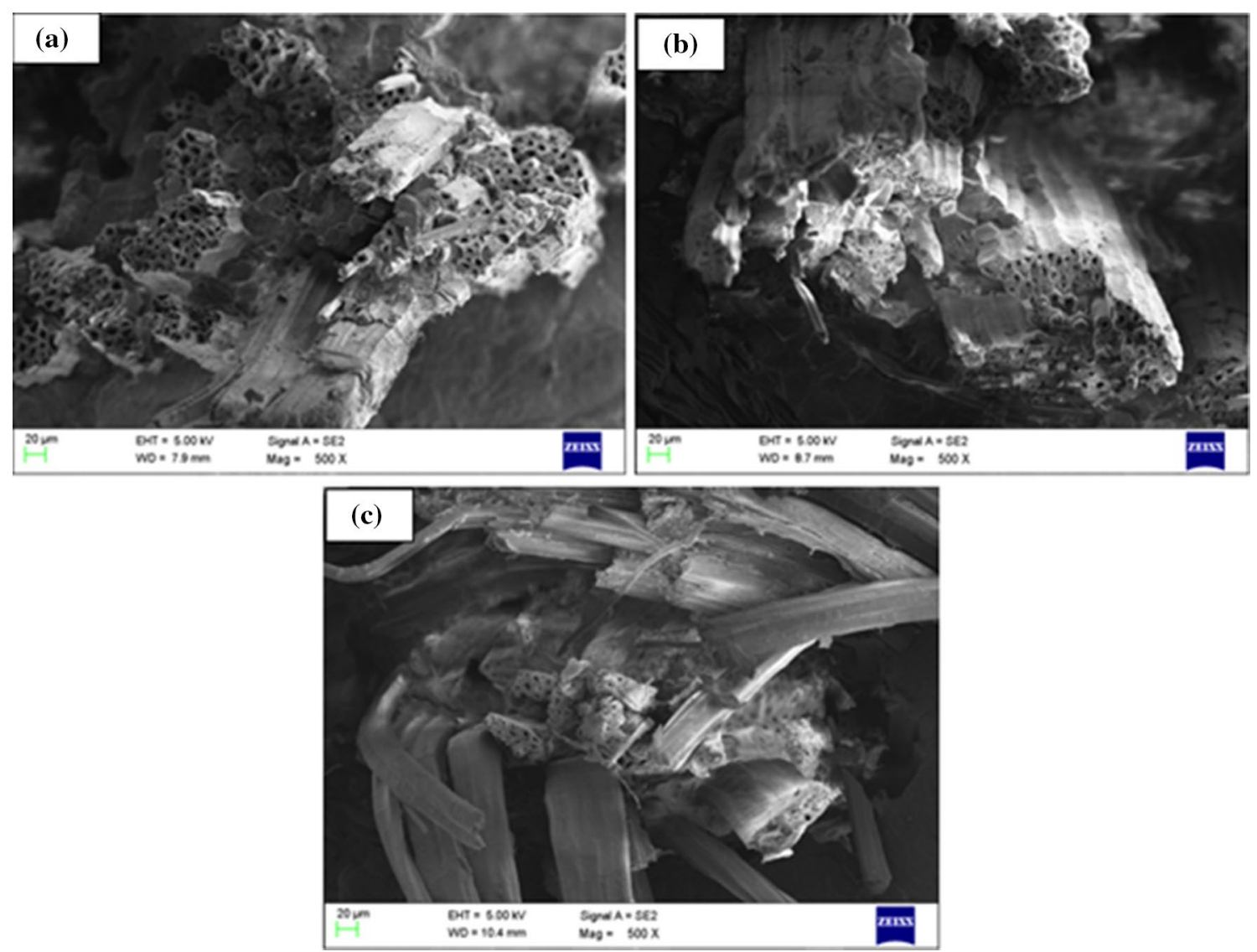

Fig. 6 Scanning electron microscope images of fabricated specimen 
4. The morphological study revealed the influence of molding process parameters on the tensile behaviour of the fabricated composites.

5. The fabricated composite can certainly be considered as a promising material for non-load bearing lightweight materials; used in partition panels, automobiles, furniture and packaging industries etc.

Acknowledgements We would like extend our heartfelt gratitude to MU recurrent project CRPO/EiT-M/Large/Recurrent /001/2010 registration number; for sponsoring this study as a large scale research project and Mekelle University School of Mechanical and Industrial Engineering for its unlimited provision of access to the lab.

\section{Compliance with ethical standards}

Conflict of interest The author declare that they have no competing interests.

\section{References}

1. Yallew TB, Aregawi S, Kumar P, Singh I (2018) Response of natural fiber reinforced polymer composites when subjected to various environments. Int J Plast Technol 22:56-72

2. Mukhopadhyay S, Srikanta R (2008) Effect of ageing of sisal fibres on properties of sisal-polypropylene composites. Polym Degrad Stab 93:2048-2051

3. Yallew TB, Kumar P, Singh I (2016) Mechanical behavior of nettle/ wool fabric reinforced polyethylene composites. J Nat Fibers 13(5):610-618

4. Chand N, Dwivedi UK (2006) Effect of coupling agent on abrasive wear behaviour of chopped jute fibre-reinforced polypropylene composites. Wear 261:1057-1063

5. Eleiche AM, Amin GM (1986) The effect of unidirectional cotton fibre reinforcement on the friction and wear characteristics of polyester. Wear 112:67-78

6. Larbig H, Scherzer H, Dahlke B, Pol-trock R (1998) Natural fibre reinforced foams based on renewable resources for automotive interior applications. J Cell Plast 34:361-379

7. Nirmal U, Yousif BF, Rilling D, Brevern PV (2010) Effect of betelnut fibres treatment and contact conditions on adhesive wear and frictional performance of polyester composites. Wear 268:1354-1370

8. El-Tayeb NSM (2008) A study on the potential of sugarcane fibres/polyester composite for tribological applications. Wear 265:223-235
9. Gujjala R,Ojha S, Acharya SK, Pal SK (2013) Mechanical properties of woven jute-glass hybrid-reinforced epoxy composite. J Compos Mater 48(28):3445-3455

10. Khan JA, Khan MA, Islam R (2013) Mechanical, thermal and degradation properties of jute fabric-reinforced polypropylene composites: effect of potassiumpermanganateas oxidizing agent. Polym Compos 34(5):671-680

11. El-Shekeil YA, Sapuan SM, Abdan K, Zainudin ES (2012) Influence of fibre content on the mechanical and thermal properties of Kenaf fibre reinforced thermoplastic polyurethane composites. Mater Des 40:299-303

12. Sangthong S, Pongprayoon T, Yanumet N (2009) Mechanical property improvement of unsaturated polyester composite reinforced with admicellar-treated sisal fibres. Compos $\mathrm{A}$ 40:687-694

13. Bledzki AK, Jaszkiewicz A, Scherzer D (2009) Mechanical properties of PLA composites with man-made cellulose and abaca fibres. Compos A 40:404-412

14. Zampaloni M, Pourboghrat F, Yankovich SA, Misra M (2007) Kenaf natural fiber reinforced polypropylene composites: a discussion on manufacturing problems and solutions. Compos A Appl Sci Manuf 38(6):1569-1580

15. Srinivasa CV, Arifulla A, Goutham N, Santhosh T, Jaeethendra HJ, Ravikumar RB, Santhosh Kumar DG, Ashish J, Anil SG (2011) Static bending and impact behaviour of areca fibers composites. Mater Des 32:2469-2475

16. Saravanan K, Dhurai B (2013) Effect of process parameters on impact strength of short jute fibre reinforced polypropylene composite board. Indian J Fibre Text Res 38:92-95

17. Dweib MA, Hu B, Donnell AO, Shenton HW, Wool RP (2004) All natural composite sandwich beams for structural applications. Compos Struct 63:147-157

18. Torres FG, Arroyo OH, Gomez C (2007) Processing and Mechanical Properties of Natural Fiber Reinforced Thermoplastic Starch Bio-composites. J Thermoplast Compos Mater 20:207-223

19. Takemura K, Minekage $Y$ (2007) Effect of molding condition on tensile properties of hemp fiber reinforced composite. Adv Compos Mater 16(4):385-394

20. Khondker OA, Ishiaku US, Nakai A, Hamada H (2005) Fabrication and mechanical properties of unidirectional jute/PP composites using jute yarns by film stacking method. J Polym Environ 13(2):115-126

Publisher's Note Springer Nature remains neutral with regard to jurisdictional claims in published maps and institutional affiliations. 